\section{Diminished Responsibility}

Robert L. Heilbronner

Chicago Neuropsychology Group, Chicago, IL, USA

\section{Definition}

Diminished responsibility refers to mitigating circumstances of a crime that justify a reduced sentence. This form of defense is also referred to as the "partial responsibility doctrine." Mitigating circumstances are raised in court at the time of sentencing. Thus, diminished responsibility is not solely related to issues regarding intent and is distinct from the diminished capacity defense. For example, this form of defense was utilized in People v. Poddar (1974), which preceded the Tarasoff case, in which the defendant intended to kill his girlfriend, but did so as a result of stress created by American relationships, since Poddar was only familiar with arranged marriages within Indian culture. It is evident, from this example, that the diminished responsibility defense does not argue lesser intent (e.g., diminished capacity defense) and does not argue for insanity. Instead, it argues for circumstantial factors, in this case cultural, being at least partially responsible for the act and thus warranting a lesser sentence. This defense, however, is rarely permitted, and it was not allowed in People v. Poddar. Currently, the diminished responsibility defense is only rarely employed, and it is typically only permitted during the sentencing phase of death penalty cases.

\section{Cross-References}

- Actus Rea

- Diminished Capacity

$>$ Insanity

- Irresistible Impulse

> Mens Rea

\section{References and Readings}

Denney, R. L., \& Wynkoop, T. F. (2000). Clinical neuropsychology in the criminal forensic setting. Journal of Head Trauma Rehabilitation, 15, 804-828.

People v. Poddar, 10 Cal. 3d 750, 518. P 2d 342, III Call Rptr. 910 (1974).

Yates, K. F., \& Denney, R. L. (2008). Neuropsychology in the assessment of mental state at the time of the offense. In R. Denney \& J. Sullivan (Eds.), Clinical neuropsychology in the criminal forensic setting. New York: Guilford. 